\title{
Correction to: Neutrophil/lymphocyte ratio and platelet/lymphocyte ratio in Behçet's disease: which and when to use?
}

\author{
Marwa Hammad $^{1}$ (D) $\cdot$ Omaima Zakaria Shehata ${ }^{1} \cdot$ Shaimaa Mohamed Abdel-Latif ${ }^{1} \cdot$ Amany Mohamed Mohiey El-Din $^{2}$
}

Published online: 4 May 2019

(C) International League of Associations for Rheumatology (ILAR) 2019

\section{Correction to: Clin Rheumatol (2018) 37:2711-2817 https://doi.org/10.1007/s10067-018-4194-z}

The authors wish to acknowledge that whilst this study [1] and that published in Hammad et al [2] explore different areas blood cell ratios and serum endocan, respectively - the reader may identify some similarities between the papers owing to the same patient cohort being analysed in both studies.

Furthermore, the authors wish to confirm that written permission has retrospectively been obtained for the aggregate data presented in Table 1 of this paper.

\section{References}

1. Hammad M, Shehata OZ, Abdel-Latif SM et al (2018) Neutrophil/lymphocyte ratio and platelet/lymphocyte ratio in Behçet's disease: which and when to use?. Clin Rheum 37:2811-2817

2. Hammad M, Abdel-Latif SM, Shehata, OZ et al (2019) Clinical significance of endocan in Behçet's disease patients: A potential marker of disease activity. The Egyptian Rheumatologist 41:59-64. https://doi.org/10.1016/j.ejr. 2018.04.002

Publisher's note Springer Nature remains neutral with regard to jurisdictional claims in published maps and institutional affiliations.

The online version of the original article can be found at https://doi.org/ 10.1007/s10067-018-4194-z

Marwa Hammad

marwahany22@hotmail.com

1 Rheumatology and Rehabilitation, Faculty of Medicine, Zagazig University, Zagazig, Egypt

2 Clinical pathology, Faculty of Medicine, Zagazig University, Zagazig, Egypt 